\title{
GDP Spatialization and Economic Differences in South China Based on NPP-VIIRS Nighttime Light Imagery
}

\author{
Min Zhao ${ }^{1,2,3} \mathbb{D}$, Weiming Cheng ${ }^{3,4, *} \mathbb{D}$, Chenghu Zhou ${ }^{1,2,3,4}$, Manchun Li ${ }^{1,2}$, Nan Wang ${ }^{3,5}$ \\ and Qiangyi Liu ${ }^{3,5}$ \\ 1 School of Geographic and Oceanographic Sciences, Nanjing University, Nanjing 210023, China; \\ zhaom@1reis.ac.cn (M.Z.); zhouch@1reis.ac.cn (C.Z.); limanchun@nju.edu.cn (M.L.) \\ 2 Collaborative Innovation Center of South China Sea Studies, Nanjing 210023, China \\ 3 State Key Laboratory of Resources and Environmental Information Systems, Institute of Geographic \\ Sciences and Natural Resources Research, Chinese Academy of Sciences, Beijing 100101, China; \\ wangn.14s@igsnrr.ac.cn (N.W.); liuqy.15s@igsarr.ac.cn (Q.L.) \\ 4 Jiangsu Center for Collaborative Innovation in Geographic Information Resource Development and \\ Application, Nanjing 210023, China \\ 5 University of Chinese Academy of Sciences, Beijing 100049, China \\ * Correspondence: chengwm@1reis.ac.cn; Tel.: +86-10-6488-9777
}

Academic Editors: Qihao Weng, Guangxing Wang, George Xian, Hua Liu and Prasad S. Thenkabail Received: 27 April 2017; Accepted: 29 June 2017; Published: 1 July 2017

\begin{abstract}
Accurate data on gross domestic product (GDP) at pixel level are needed to understand the dynamics of regional economies. GDP spatialization is the basis of quantitative analysis on economic diversities of different administrative divisions and areas with different natural or humanistic attributes. Data from the Visible Infrared Imaging Radiometer Suite (VIIRS), carried by the Suomi National Polar-orbiting Partnership (NPP) satellite, are capable of estimating GDP, but few studies have been conducted for mapping GDP at pixel level and further pattern analysis of economic differences in different regions using the VIIRS data. This paper produced a pixel-level $(500 \mathrm{~m} \times$ $500 \mathrm{~m}$ ) GDP map for South China in 2014 and quantitatively analyzed economic differences among diverse geomorphological types. Based on a regression analysis, the total nighttime light (TNL) of corrected VIIRS data were found to exhibit $R^{2}$ values of 0.8935 and 0.9243 for prefecture GDP and county GDP, respectively. This demonstrated that TNL showed a more significant capability in reflecting economic status $\left(R^{2}>0.88\right)$ than other nighttime light indices $\left(R^{2}<0.52\right)$, and showed quadratic polynomial relationships with GDP rather than simple linear correlations at both prefecture and county levels. The corrected NPP-VIIRS data showed a better fit than the original data, and the estimation at the county level was better than at the prefecture level. The pixel-level GDP map indicated that: (a) economic development in coastal areas was higher than that in inland areas; (b) low altitude plains were the most developed areas, followed by low altitude platforms and low altitude hills; and (c) economic development in middle altitude areas, and low altitude hills and mountains remained to be strengthened.
\end{abstract}

Keywords: GDP estimation; VIIRS; nighttime light; geomorphological types; South China

\section{Introduction}

Gross domestic product (GDP) is an important indicator of the economic performance of a country or region. With the accelerating process of urbanization, development patterns of different regions present more prominent regional differences. However, there are many problems to measure GDP using socioeconomic statistics, such as the inconsistency of statistical scales and the uniformity of 
data within the statistical unit, which make it difficult to reflect differences in regional economic development at fine scales. There are also problems with inconsistent borders during overlay analysis between the statistical data based on administrative units, and vegetation patterns and natural disaster data based on geographic units. Identifying how to accurately measure GDP at fine scales is of great importance to understanding the dynamic changes in regional economies and meeting the needs of interdisciplinary research.

Compared with traditional socioeconomic census, remote sensing imagery has obvious advantages in describing the spatial distribution of GDP. Nighttime light data are frequently used to describe the intensity of economic activities on the earth surface, and have been widely used in the estimation of socioeconomic parameters.

Previous studies have used the nighttime light data from the Defense Meteorological Satellite Program-Operational Linescan System (DMSP-OLS) to investigate economic activities at different scales. For example, Elvidge et al. [1] found a high correlation between the area lit and GDP for 21 counties in North America using the DMSP-OLS nighttime light data. Similar studies were carried out in the European Union countries, China and the United States, revealing that the regression coefficients of the total nighttime light (TNL) and GDP were in the range of 0.8 to 0.9 [2-4]. In addition, studies have produced maps of economic activity at $5 \mathrm{~km}$ and $1 \mathrm{~km}$ resolution based on the relationships between economic parameters and nighttime radiance from DMSP-OLS nighttime light data $[5,6]$.

Despite the strong capacity of DMSP-OLS nighttime imagery to investigate economic activities at both global and regional scales, the lack of on-board radiometric calibration and limited radiometric detection capacity inevitably reduce the correlations between economic activities and detected nighttime light $[7,8]$. A new generation of nighttime light data collected by the Visible Infrared Imaging Radiometer Suite (VIIRS) carried by the Suomi National Polar-Orbiting Partnership (NPP) satellite was released freely in 2013 [9,10]. The NPP-VIIRS data have a higher resolution (about $500 \mathrm{~m}$ ) than the $1 \mathrm{~km}$-resolution DMSP-OLS data. Moreover, the wider radiometric detection range solves over-saturation problems and the on-board radiometric calibration increases the data quality [10]. Several studies have suggested that the NPP-VIIRS data might be more indicative for economic development than DMSP-OLS data at both provincial and city scales because of their more positive responses to economic indicators [11-13]. At present, studies of GDP estimation using NPP-VIIRS data are relatively new, and most focus on responses of nighttime light radiance to economic variables at regional scales. However, studies using NPP-VIIRS data for the estimation of economic variables at pixel-level scales are less common, and moreover, no analysis has been done on the regional differentiation of economic maps simulated from NPP-VIIRS data.

Although previous studies utilized night light brightness for quantitatively estimating and mapping socioeconomic activities differed slightly in their approaches and scopes, one common point is that their focus is often confined to urbanization processes and anthropogenic activity intensities. The land surface, which supports human life and production, however, has received less attention. As a natural factor restricting the urban expansion and demographic dynamics, the role of topography and geomorphology cannot be ignored. A fully understanding of spatial-temporal differences of economic status among different terrain and geomorphological types is a first step in exploring the complex interactions between landform and anthropogenic activities, and contributes to provide decision-making for a region's sustainable planning and development.

South China contains not only the highly-developed Pearl River Delta region, but also southwestern poverty-stricken areas, reflecting large differences in regional economies. As the major economic zone in the northern part of the South China Sea, fully understanding its economic status can help to provide a basis for China's development planning and policy formulation, and also offer decision support for the 21st Century Maritime Silk Road. In this study, the spatial distribution of GDP at $500 \mathrm{~m} \times 500 \mathrm{~m}$ in South China in 2014 was simulated using NPP-VIIRS data, and the economic differences among diverse geomorphological types were quantitatively analyzed. Firstly, a method 
was proposed to correct the original NPP-VIIRS data. Secondly, four nighttime light indices from the corrected data over South China at both prefecture and county levels were calculated. They were subsequently applied in the regression analysis between nighttime light indices and GDP. Thirdly, the best regression model was selected to simulate the pixel-level GDP and the final GDP map was produced using a GDP linear calibration model. Finally, by overlaying with the basic geomorphological types in South China, the total GDP and GDP intensity among different geomorphological units in South China were quantitatively calculated to analyze the intensity of economic activities in different geomorphological types.

\section{Case Study Area and Data}

\subsection{Case Study Area}

South China $\left(104^{\circ} 25^{\prime} \mathrm{E}-117^{\circ} 20^{\prime} \mathrm{E}, 18^{\circ} 9^{\prime} \mathrm{N}-26^{\circ} 24^{\prime} \mathrm{N}\right)$ is one of the seven geographical divisions in China with a total area of $447,881 \mathrm{~km}^{2}$ (Figure 1). It is located in the southern part of China and consists of three provinces (Guangdong, Guangxi and Hainan), including 38 prefecture-level cities, and 286 county-level cities, districts or counties. Because not all statistical data at the level of county administrative units can be obtained, some districts were consolidated to generate several new county-level units for analysis in this study.

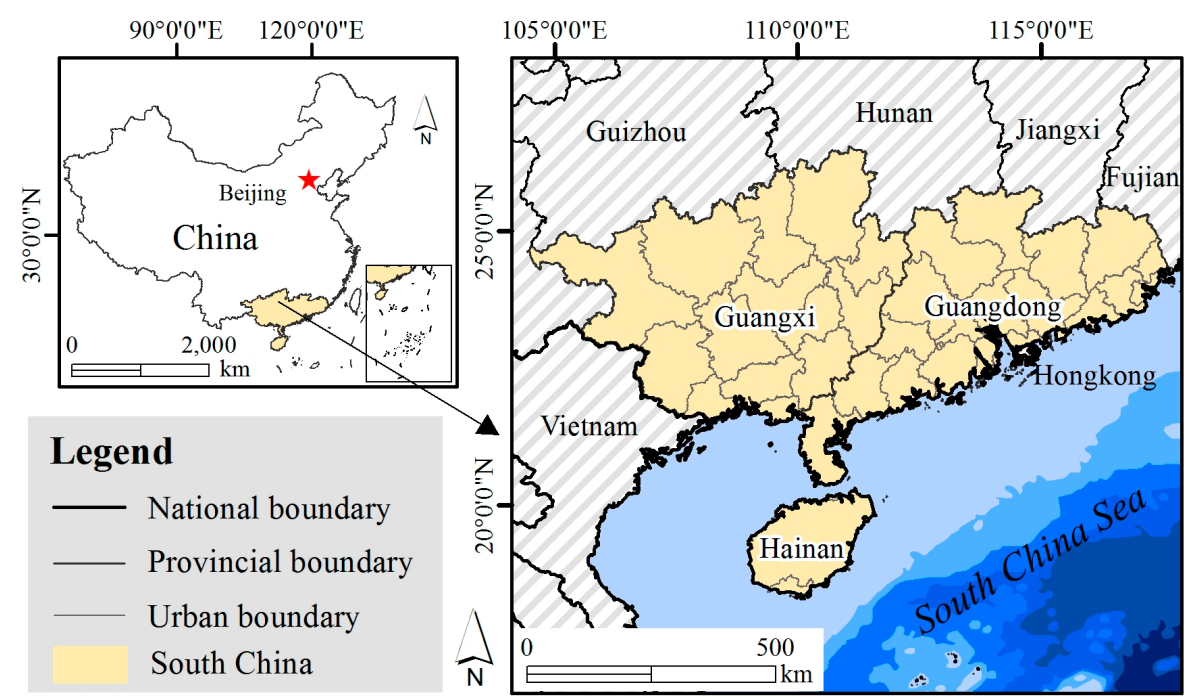

Figure 1. An overview of the South China study area.

\subsection{Data Collection}

\subsubsection{Visible Infrared Imaging Radiometer Suite (VIIRS) Nighttime Light Data}

The version 1 series of global VIIRS nighttime light images for the year 2014 were provided by the Earth Observation Group, National Geophysical Data Center (NGDC) at the National Oceanic and Atmospheric Administration (NOAA) (downloaded from https:/ / www.ngdc.noaa.gov/eog/ viirs/download_monthly.html). The VIIRS Day/Night Band cloud free composites data are produced monthly, and contain spatially gridded nocturnal radiance values across human settlements at a spatial resolution of 15 arc-seconds spanning the latitudinal zones of $65^{\circ} \mathrm{S}-75^{\circ} \mathrm{N}$. In this study, the monthly nighttime light images for China were extracted and projected to an Albers equal area conic projection with a spatial resolution of $500 \mathrm{~m}$. Then, the VIIRS nighttime light images for South China, spanning months 1-12 for the year 2014, were extracted. A composite VIIRS nighttime light image for South China was generated by averaging pixel brightness from the 12 images, and formed the original VIIRS data for South China in this study (Figure 2a). 


\subsubsection{Defense Meteorological Satellite Program (DMSP) Nighttime Light Data}

The version 4 composite DMSP-OLS stable nighttime light data, derived from NOAA/NGDC, are grid-based annual data composites spanning 1992-2012 with a digital number (DN) between 0 and 63 and a 30 arc-second (approximately $1 \mathrm{~km}$ at the equator) spatial resolution for pixels. To reduce the yearly variations and response differences among sensors, a second order regression model $[14,15]$ was used to empirically calibrate the annual nighttime light products, which were matched with the composite of F12 in 1999. As the corrected data in 2013 had not been available, the closest available corrected data were used for this research. Thus, the imagery for China in 2012 was projected into the Albers equal area conic projection and resampled to a spatial resolution of $500 \mathrm{~m} \times 500 \mathrm{~m}$. The DMSP imagery for South China in this study was extracted from processed DMSP-OLS data for China (Figure 2b).
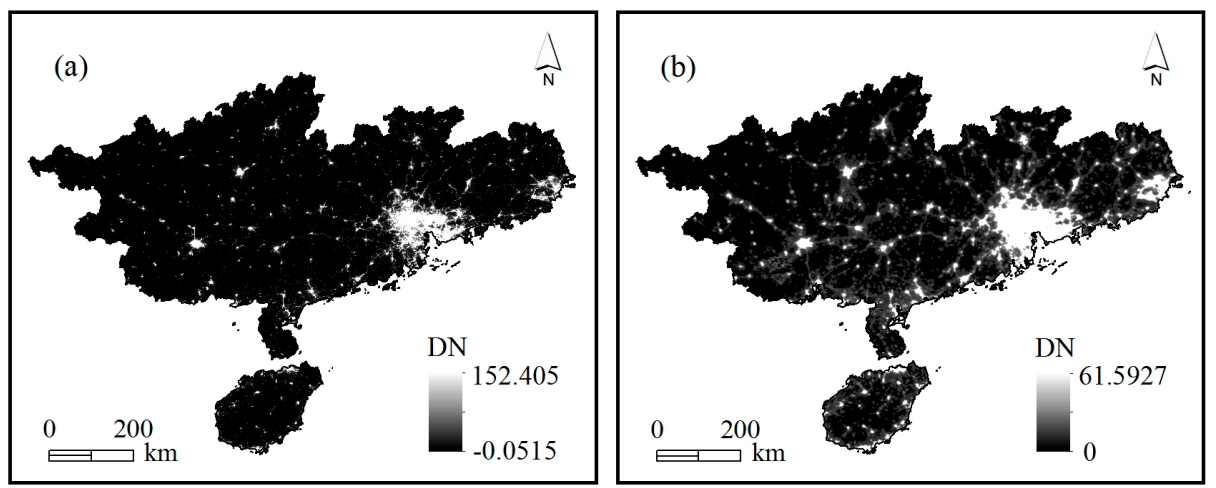

Figure 2. Spatial distribution of nighttime light data across South China: (a) the composite National Polar-Orbiting Partnership-Visible Infrared Imaging Radiometer Suite (NPP-VIIRS) nighttime light brightness in 2014; and (b) the corrected Defense Meteorological Satellite Program-Operational Linescan System (DMSP-OLS) nighttime light brightness in 2012.

\subsubsection{Statistical Economic Data}

Applications of nighttime light data for quantitatively estimating socioeconomic parameters have been well documented in previous studies using statistical data $[5,16]$. To investigate the quantitative relationships between VIIRS nighttime light signals and GDP for South China in 2014, the statistical GDP data for prefecture- and county-level units in South China were collected from the 2015 China City Statistical Yearbook, 2015 Guangdong Statistical Yearbook, 2015 Guangxi Statistical Yearbook, and 2015 Hainan Statistical Yearbook. It is noted that the 2015 China City Statistical Yearbook records all prefecture-level GDP and certain county-level GDP in 2014, whereas the provincial statistical yearbooks record the GDP for most of the county-level administrative units in provinces of Guangdong, Guangxi and Hainan in 2014. One unavoidable problem was the incompleteness and inconsistency of the statistical data from different sources, which made the work of data collation more critical. In this study, the prefecture-level GDP was obtained from the China City Statistical Yearbook, whereas the county-level GDP was mainly collected from provincial statistical yearbooks. For several county-level units with no data, county-level units belonging to the same prefecture-level unit were amalgamated and the total GDP of the newly merged units was calculated through subtraction. Based on this criterion, 38 prefecture-level and 190 county-level GDPs were summarized (Table A1). Boundaries for some county-level units were also merged to achieve spatial consistency with the corresponding statistical data.

\subsubsection{Geomorphological Data}

Geomorphological data were derived from 1:1,000,000 digital geomorphological database of China. The digital geomorphological data were obtained with visual interpretation from Landsat 
TM/ETM images, SRTM-DEM, and geology data [17]. The database contains seven data hierarchies, including basic morphology, genesis, sub-genesis, morphology, micro-morphology, slope and aspect, material composition and lithology [18]. Basic morphological types were created using two controlling factors: altitude and relief, and have been widely used in research on land cover change $[19,20]$, urbanization [21-23] and cultivated land evaluation [24,25]. In this study, data of basic morphological types for South China were extracted. Their classification standard and spatial distribution are shown in Table 1 and Figure 3.

Table 1. Characteristics of the basic geomorphological types in South China.

\begin{tabular}{cccc}
\hline Basic Geomorphological Types & Type Abbreviation & Altitude & Relief \\
\hline Low altitude plain & LAP & $<1000 \mathrm{~m}$ & $<30 \mathrm{~m}$ \\
Middle altitude plain & MAP & $1000 \mathrm{~m}-3500 \mathrm{~m}$ & $<30 \mathrm{~m}$ \\
Low altitude platform & LAPF & $<1000 \mathrm{~m}$ & $>30 \mathrm{~m}$ \\
Low altitude hill & LAH & $<1000 \mathrm{~m}$ & $<200 \mathrm{~m}$ \\
Middle altitude hill & MAH & $1000 \mathrm{~m}-3500 \mathrm{~m}$ & $<200 \mathrm{~m}$ \\
Low-relief low altitude mountain & LRLAM & $<1000 \mathrm{~m}$ & $200 \mathrm{~m}-500 \mathrm{~m}$ \\
Low-relief middle altitude mountain & LRMAM & $<1000 \mathrm{~m}$ & $200 \mathrm{~m}-500 \mathrm{~m}$ \\
Middle-relief low altitude mountain & MRLAM & $1000 \mathrm{~m}-3500 \mathrm{~m}$ & $500 \mathrm{~m}-1000 \mathrm{~m}$ \\
Middle-relief middle altitude mountain & MRMAM & $1000 \mathrm{~m}-3500 \mathrm{~m}$ & $500 \mathrm{~m}-1000 \mathrm{~m}$ \\
High-relief middle altitude mountain & HRMAM & $1000 \mathrm{~m}-3500 \mathrm{~m}$ & $1000 \mathrm{~m}-2500 \mathrm{~m}$ \\
\hline
\end{tabular}

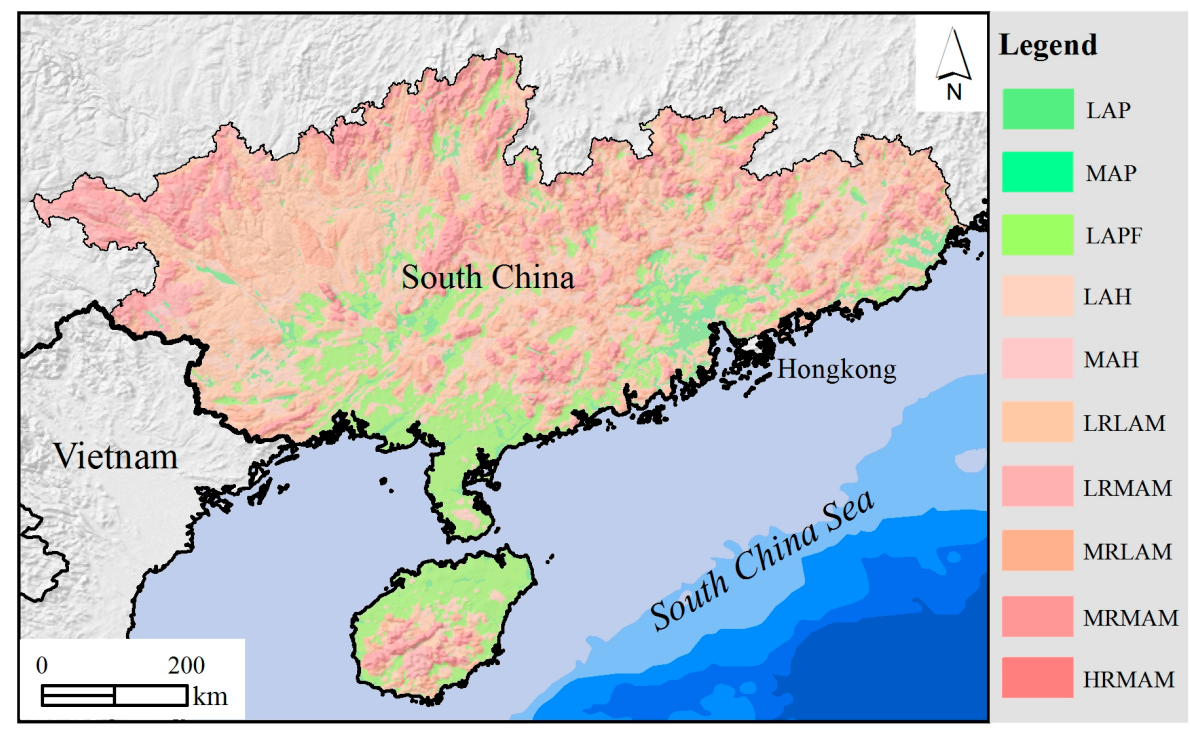

Figure 3. Spatial distribution of the basic geomorphological types in South China.

\section{Methods}

\subsection{Correction of the VIIRS Nighttime Light Data}

The NPP-VIIRS data are preliminary product, which have not been filtered to screen out lights from auroras, fires, gas flares, volcanoes, and background noise [10,26]. These confounding factors are irrelevant to economic activities, and can limit the accuracy and reliability in GDP estimation.

In this study, a sequence of preprocessing procedures was employed to reduce these interference factors in the original NPP-VIIRS data. Based on the hypothesis noted in previous studies that lit areas in the DMSP-OLS are the same as those in the NPP-VIIRS data in adjacent years $[11,13,27]$, it is appropriate to assign same lit areas in similar years. Compared with the VIIRS data in 2014, the closest corrected DMSP-OLS data were available for the year 2012. Accordingly, the 2012 corrected DMSP-OLS data were used for lighting correction of VIIRS nighttime light data in 2014. The processing procedures 
are shown in Figure 4. Firstly, a mask with all pixels with DN value of 0 from the DMSP-OLS data in 2012 was generated to get the dark background of DMSP-OLS data in 2012. Next, lit areas in the potentially dark background of VIIRS data in 2014 were generated by extraction analysis. Based on that, Google Earth images were applied to extract the corresponding urban built area by visual interpretation. The real dark background of VIIRS data in 2014 was obtained by removing the urban regions of lit areas in the potential background. Lastly, we assigned the values of pixels that fell within the real dark background to 0 , leaving the initial corrected VIIRS data without the background noise. The initial corrected data could provide a fair performance for GDP estimation, but a few outliers which were probably caused by stable lights from fires of oil or gas also needed to be corrected. Cities of Shenzhen, Zhuhai and Guangzhou in Guangdong province, Liuzhou and Nanning in Guangxi province, and Haikou and Sanya in Hainan province are the most developed cities in each province. Therefore, pixel values of other areas should not exceed values of these cities theoretically. The highest DN value across these cities in each province was used as a threshold to detect outliers in each province. Pixels whose DN value were larger than the threshold were assigned to the maximum DN value within the pixel's immediate eight neighbors. If the maximum DN value was also larger than the threshold, the values of pixels of its eight-neighborhood area were selected for a second comparison. After this process, the final corrected VIIRS data were generated with all pixels in each province less than the threshold.

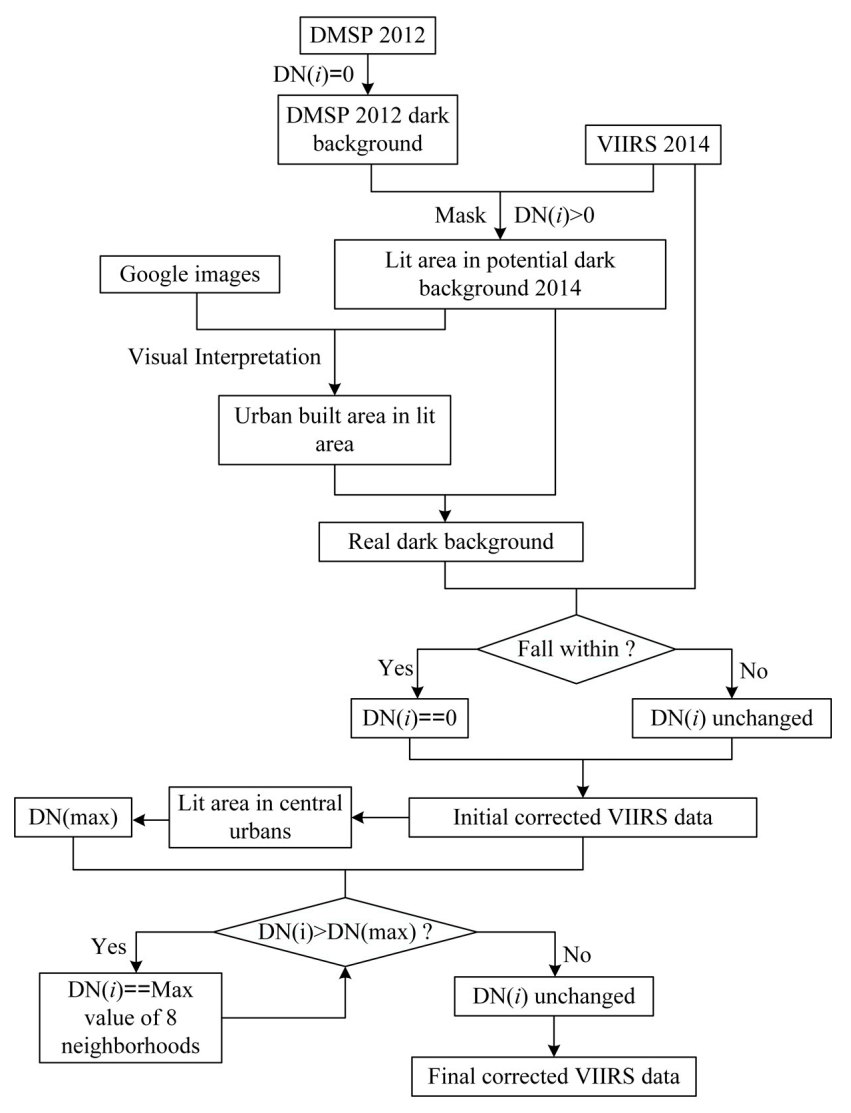

Figure 4. Processing flow chart for lighting correction of VIIRS nighttime light data.

\subsection{Calculation of Nighttime Light Indices}

Nighttime light indices have been used to reflect socioeconomic level, such as total nighttime light (TNL), average nighttime light intensity (I), proportion of intensely lit area (S), and compounded nighttime light index (CNLI). TNL refers to the sum of the DN value of lighting within an administrative unit $[12,13,27]$. I is the ratio of TNL to the maximum nighttime light within an 
administrative unit $[28,29]$. $S$ is defined as the ratio of the lit pixel area to the area of administrative unit $[12,29]$. CNLI is identified as the product of average light intensity and proportion of intensely lit area [30]. These nighttime light indices are calculated using following equations:

$$
\begin{gathered}
V T N L=\sum\left(D N_{i} \times n_{i}\right), \\
V I=V T N L /\left(D N_{\text {max }} \times N_{L}\right), \\
V S=A_{N} / A, \\
V C N L I=V I \times V S,
\end{gathered}
$$

where VTNL, VI, VS, VCNLI denote the value of TNL, I, S, and CNLI, respectively; $D N_{i}$ and $n_{i}$ denote the pixel value of the $i$ level lighting and its corresponding pixel number within an administrative unit, respectively; $D N_{\max }$ and $N_{L}$ denote the maximum value of lighting and the total pixel number of lit area within an administrative unit, respectively; and $A_{N}$ and $A$ denote the area of lit pixels within an administrative unit and the total area of the administrative unit, respectively.

\subsection{Regression Model and Simulation of GDP}

To date, many regression models have been used for delineating the quantitative relationships between socioeconomic variables and VIIRS nighttime light signals [12,13,27,28,31,32]. Because lighting variables and socioeconomic parameters are different for diverse research scales, a single regression model may not be able to estimate the GDP accurately at different levels of administrative unit. To make the simulated GDP at the pixel level closer to the statistical data, four regression models (linear model, quadratic polynomial model, power function, and exponential function), together with the four commonly used light indices mentioned above, were selected to evaluate the quantitative relationships between VIIRS light indices and GDP in both prefectural-level and county-level units. Based on these regression analyses, the optimal regression model and light index was used to simulate GDP. A relative error was used to evaluate the capacity of the best light index to predict GDP.

$$
e=\left(g^{\prime}-g\right) / g
$$

where $g$ denotes the real GDP and $g^{\prime}$ denotes the calculated GDP.

\subsection{GDP Spatialization: Correction of Simulated GDP}

To map the spatial distribution of GDP (GDP spatialization), GDP at the administrative unit scale needs to be disaggregated to the pixel scale. However, high deviations may occur because the simulated GDP at pixel level based on the optimal regression model was calculated directly using the light pixel value rather than the total nighttime light value $[11,13,27]$. Therefore, it is necessary to make corrections of the simulated GDP for each pixel in the administrative unit. The equation for correcting the simulated GDP at pixel level is shown below [33]:

$$
G D P_{P}=\left(G D P_{t} / G D P_{s}\right) \times G D P_{i}
$$

where $G D P_{P}$ represents the corrected GDP of a pixel, $G D P_{t}$ is the statistical GDP of each administrative unit, $G D P_{S}$ is the sum of corresponding simulated GDP at pixel level by the optimal regression model, and $G D P_{i}$ is the simulated GDP of a pixel.

\section{Results}

\subsection{Correction Results for the VIIRS Nighttime Light Data}

Figure 5a shows the corrected NPP-VIIRS data for South China in 2014. Figure 5b illustrates the difference between the lighting value of the corrected and original imagery. The region bounded by 
the rectangle in Figure 5a was magnified in Figures $5 c$ and 5d. As can be seen in Figure 5, the proposed lighting correction method could correct some lit areas with weak light and abnormally strong light, as well as pixels with negative DN values in the original NPP-VIIRS data. The range of difference between the corrected lighting and the original lighting was from -106.703 to 0.052 , and 1,791,484 pixels were corrected. Sampling area No. 1 in Figure 5 was located in Hechi city, Guangxi Province. Some bright areas located in the northwest of Dahua County (Figure 5c) became dimmer in the corrected data (Figure 5d). The lit area No. 1 indicated by the red circle and yellow arrow in Figure 5c was the Yantan Reservoir. Lights before correction might be caused by vessels working at night. The sampling area No. 2 in Figure 5 was in Nanning city, Guangxi Province. The lit area No. 2 indicated by the red circle and yellow arrow was a state road across the southeast of Mashan county, which was removed in the corrected imagery (Figure 5d). The lit area of reservoir and state road in Figure 5 were located in suburb area, where light from vessels and vehicles were not persistent. Comparison results show that our correction method can remove the background noise and short-time lighting from VIIRS data. The corrected VIIRS data we used were focused on simulation of stable GDP and therefore might ignore that of non-persistent GDP. Because all raster were processed using a unified standard, the corrected VIIRS data should be relatively reliable for GDP estimation.
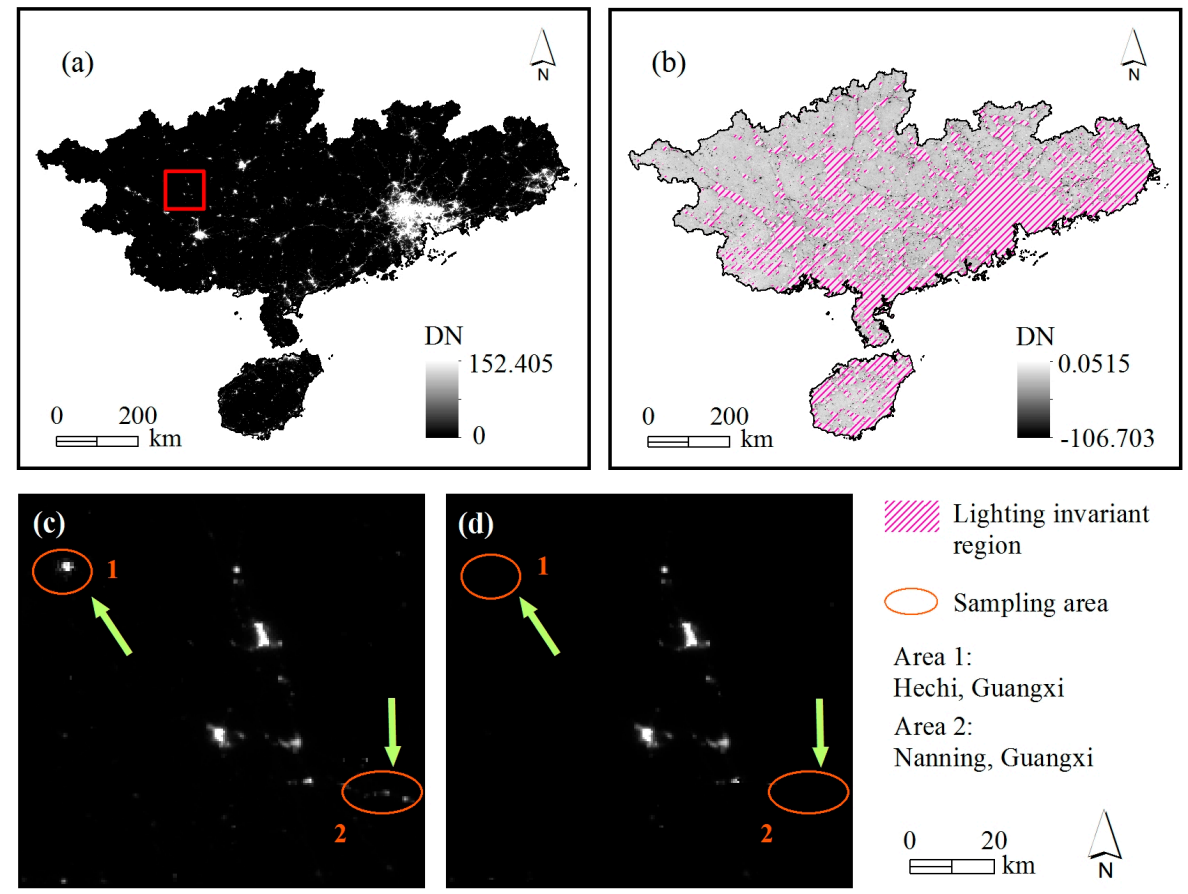

Figure 5. (a) The corrected VIIRS nighttime light data for South China in 2014. The region bounded by the red rectangle is the sampling area. (b) The difference between the corrected and original lighting. The red shaded area is the lit area where the lighting value is not modified. (c) The original; and (d) corrected imagery of sampling region are Hechi (area No. 1) and Nanning (area No. 2). The two example lit areas that were removed during correction are indicated by red circles and yellow arrows.

\subsection{Regression Results}

For the corrected NPP-VIIRS data, obvious quadratic polynomial relationships between the GDP and four light indices at the prefecture level were found (Figure 6). At the prefecture level, the $R^{2}$ value of the TNL from corrected NPP-VIIRS data and GDP was 0.8935 (Figure 6a), whereas that of other indices were much lower with $R^{2}$ of $0.4192,0.3125$ and 0.4289 for I, S and CNLI, respectively (Figure 6b-d). Clearly, the most significant statistical relationship between the TNL and the GDP was found at the prefectural-level scale in South China, indicating that this index is suitable for GDP estimation. 

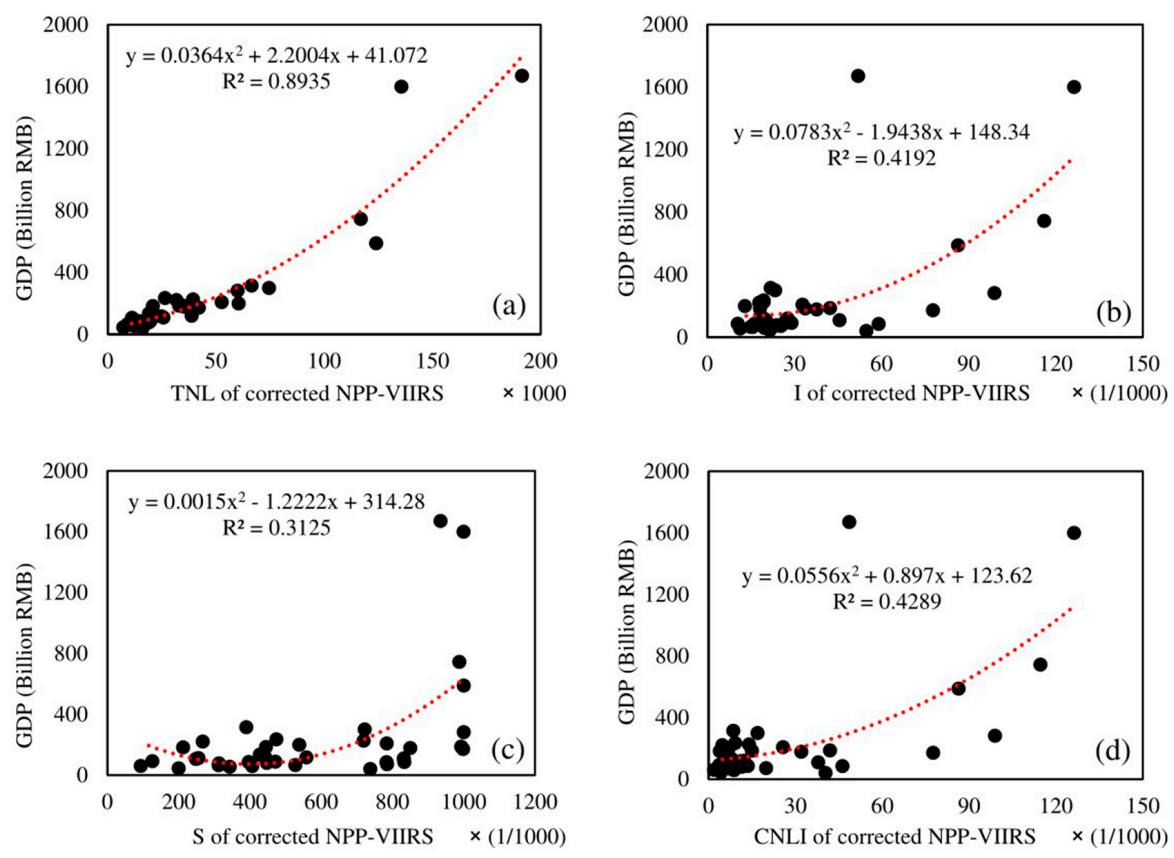

Figure 6. Statistical relationships between GDP and four light indices for corrected VIIRS data at the prefecture level: (a) the total nighttime light (TNL); (b) average nighttime light intensity (I); (c) proportion of intensely lit area (S); and (d) compounded nighttime light index (CNLI).

The regression results at the county level revealed various relationships between GDP and the four light indices (Figure 7). The quantitative relationship between GDP and TNL $\left(R^{2}=0.9243\right)$ was portrayed by a quadratic polynomial model (Figure 7a), whereas that between GDP and the other light indices showed weak correlations. I value showed a much weaker response to GDP $\left(R^{2}=0.1921\right)$, using a quadratic polynomial model (Figure $7 \mathrm{~b}$ ). Figure $7 \mathrm{c}$ represented a weak exponential relationship between GDP and S with an $R^{2}$ value of 0.5122 under the best simulation. The quantitative relationship between GDP and CNLI $\left(R^{2}=0.5062\right)$ was simulated by a power function (Figure $7 \mathrm{~d}$ ). Similar to regression results at the prefecture scale, TNL was the best light index for simulating GDP at the county-level scale. Moreover, a more significant quadratic polynomial relationship between GDP and TNL at the county-level scale was found than that at the prefectural-level scale in South China $\left(R^{2}=0.9243\right.$ vs. $\left.R^{2}=0.8935\right)$. The outlier in Figure $6 \mathrm{~b}$,d represented processed results for Guangzhou city in Guangdong province. The extremely low I and CNLI values for Guangzhou might be caused by the high value of maximum nighttime light and the large proportion of lit areas of Guangzhou in 2014 based on a combined analysis with Equations (2) and (4).

Apart from the regression analysis for the corrected NPP-VIIRS data, the TNL-GDP relationships at the prefecture and county level from the original NPP-VIIRS data were also evaluated (Figure 8). At the prefecture level, the $R^{2}$ value of the TNL from the original NPP-VIIRS data and GDP was 0.8813 , which was a little lower than that from the corrected data $\left(R^{2}=0.8935\right)$. Similarly, at the county level, the $R^{2}$ value of the TNL from the original NPP-VIIRS data and GDP was lower than that from the corrected data $\left(R^{2}=0.9140\right.$ vs. $\left.R^{2}=0.9243\right)$. In addition, a more significant quadratic polynomial relationship between the GDP and TNL at the county-level scale was found than that the prefecture-level scale in South China $\left(R^{2}=0.9140\right.$ vs. $\left.R^{2}=0.8813\right)$. 

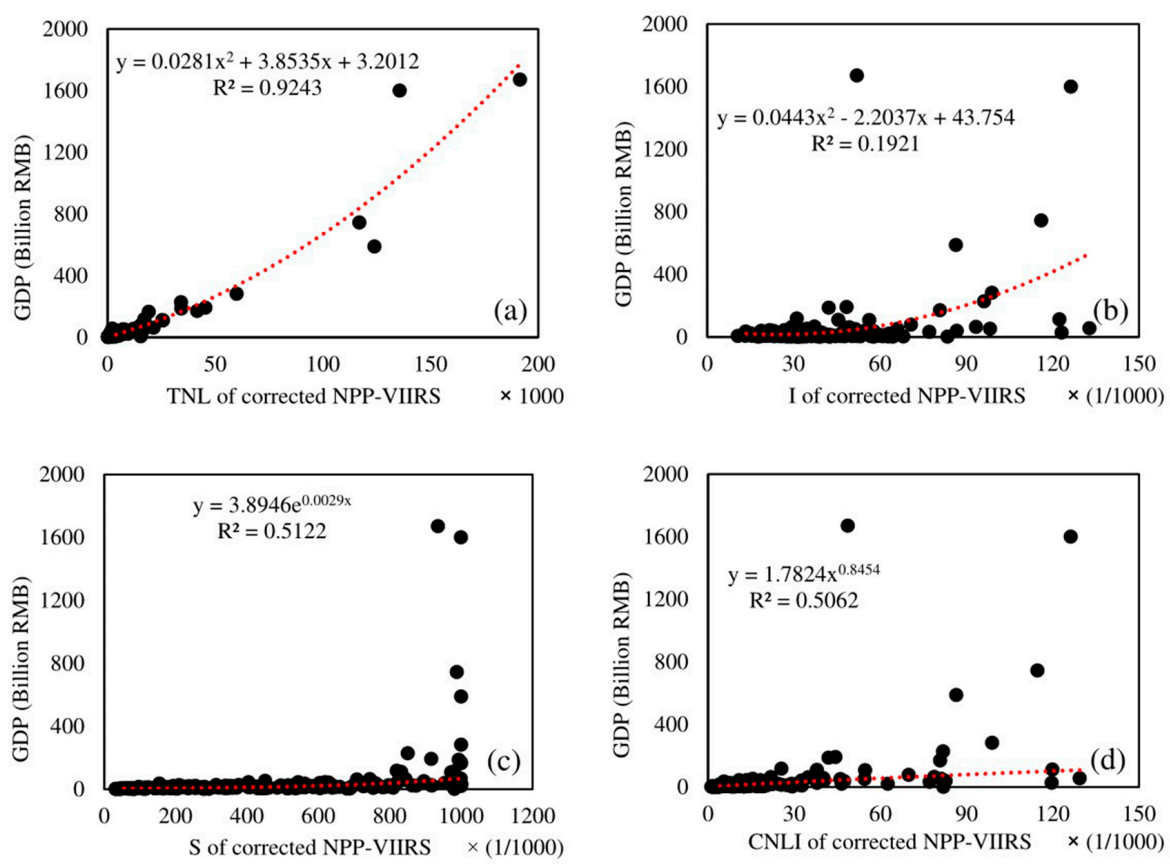

Figure 7. Statistical relationships between GDP and four light indices of corrected VIIRS data at the county level: (a) total nighttime light (TNL); (b) average nighttime light intensity (I); (c) proportion of intensely lit area (S); and (d) compounded nighttime light index (CNLI).
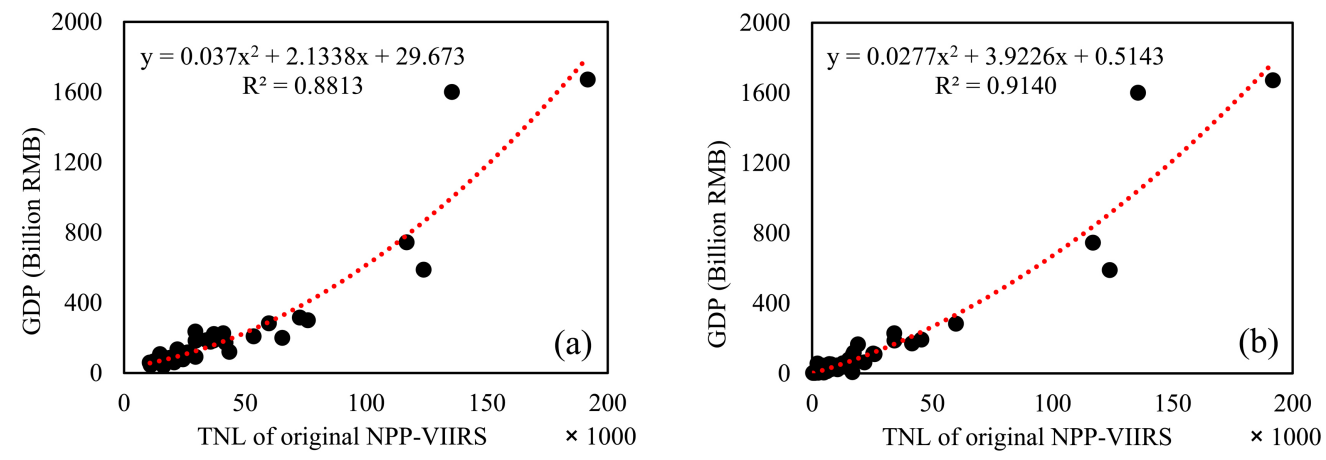

Figure 8. Statistical relationships between GDP and the total nighttime light (TNL) for the original VIIRS data at: (a) prefecture level; and (b) county level.

The absolute relative error (ARE) denotes the absolute value of relative error and has been widely used to further assess the capacity of the corrected and original NPP-VIIRS data in simulating GDP $[11,13,27]$. For ease of display, we divided the ARE into three classes: 0-25\% for high accuracy, $25-50 \%$ for moderate accuracy and $>50 \%$ for inaccuracy. The predictability for the corrected and original NPP-VIIRS imagery was quantified with the three indices listed in Table 2. Overall, the ARE values of the corrected VIIRS data were much lower than those of the original NPP-VIIRS data. At the prefecture level, there were 24 prefecture units with high accuracy in 38 regions (63.16\%) when GDP was predicted from the corrected NPP-VIIRS data, but only 22 prefecture units with high accuracy when GDP was predicted from the original data. The ratios of the inaccurate predictions from both the corrected and original NPP-VIIRS data were the same (7.89\%). At the county level, the corrected NPP-VIIRS data also showed a better capacity in simulating GDP, with $49.47 \%$ of higher accuracy compared to $46.31 \%$ from the original data. The percentage of inaccurate simulation of GDP using the corrected NPP-VIIRS data and that using the original data were the same $(24.74 \%)$. Considering that the calculated ARE was based on different scales, the difference between values of the prefecture units 
and county units was trivial. In summary, the comparative analysis of $R^{2}$ values and ARE confirmed that the corrected NPP-VIIRS data in this study were more reliable in simulating GDP at both the prefecture and county level than the original NPP-VIIRS data.

Table 2. Accuracy at different levels of the simulated GDP.

\begin{tabular}{ccccc}
\hline \multirow{2}{*}{ Region and Data } & \multicolumn{2}{c}{ Percent of Relative Error of the Simulated GDP (\%) } \\
\cline { 3 - 5 } & & High Accuracy & Moderate Accuracy & Inaccuracy \\
\hline \multirow{2}{*}{ Prefectural level } & Corrected NPP-VIIRS data & 63.16 & 28.95 & 7.89 \\
\multirow{2}{*}{ County level } & Original NPP-VIIRS data & 57.89 & 34.22 & 7.89 \\
& Corrected NPP-VIIRS data & 49.47 & 25.79 & 24.74 \\
& Original NPP-VIIRS data & 46.31 & 28.95 & 24.74 \\
\hline
\end{tabular}

\subsection{Spatialization Results}

Based on the GDP spatialization model in Section 3.4, a spatial GDP map for South China in 2014 was produced using the corrected NPP-VIIRS data and the regression model at the county level. Figure 9 shows the pixel-level $(500 \mathrm{~m} \times 500 \mathrm{~m}$ ) GDP map, which was simulated from the regression model firstly at county-level units and then corrected by formula (6). The high GDPs were concentrated in capital cities and developed cities for each province. The cities of Guangzhou, Foshan, Shenzhen, Dongguan and Zhongshan in Guangdong province; Nanning, Liuzhou and Guilin in Guangxi province; and Haikou in Hainan province all have different areas of high GDP regions (red regions), where high levels of urbanization and socioeconomic development were agglomerated. At the county level, the distribution of pixel-level GDP for South China in 2014 showed a certain spatial variability. County-level units with higher GDP levels were generally located in the southeast coastal areas, while those with lower GDP levels were distributed in western and northern inland areas. Each county-level unit had at least two different GDP levels, and administrative units with higher GDPs showed a more pronounced spatial heterogeneity. Moreover, GDPs in coastal regions of the Pearl River Delta were extremely high. Combined with the reality, county-level units with higher GDP levels were usually the localities of city districts, and those owing lower GDP levels far away from the red or orange areas were non-city districts.

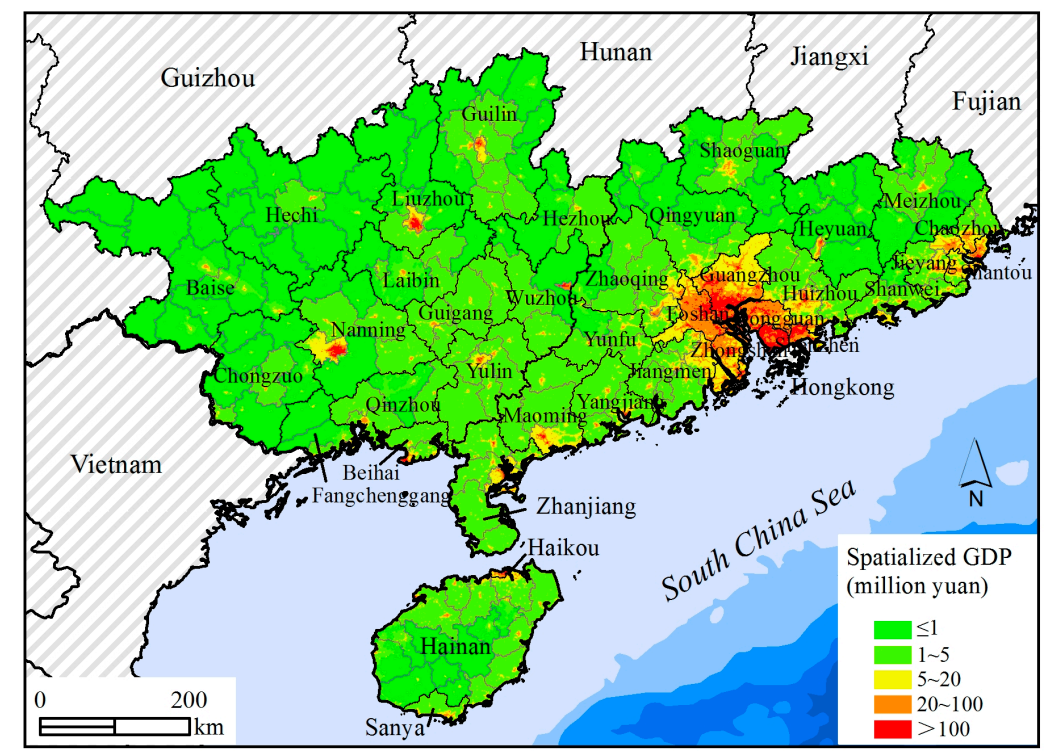

Figure 9. The pixel-level (500 m × $500 \mathrm{~m})$ GDP map for South China in 2014 . 
Comparing Figures 3 and 9, there seemed to be some correlation between GDP and geomorphological features. GDP values were generally high in regions with simple landforms. Figure 10 revealed the distribution characteristics of GDP within different geomorphological types in South China in the year of 2014. Both the total GDP and its intensity in the low altitude regions showed higher values than those in the middle altitude ones. The low altitude plain of South China had the largest GDP value and GDP intensity in 2014 with up to nearly 5,000,000 million Yuan and 66 million Yuan per square kilometer, respectively. Compared with GDPs in the low altitude plain, total GDP and its intensity were a bit lower in the units of other low altitude geomorphological types (low altitude platform, low altitude hill, low-relief low altitude mountain, and middle-relief low altitude mountain), and reflected a gradually declining trend. In the middle altitude regions, GDP intensity in the middle altitude plain areas was relative high, followed by middle altitude hills. In summary, during the year of 2014, the low altitude plain had the most active economic activities in South China, and low altitude regions were more economically developed than middle altitude regions. Moreover, plains and platforms were the main economic zones in South China, and the GDPs of mountainous areas remained to be developed. These results for the economic differences in different geomorphological types are consistent with our general understanding, which helps to verify the accuracy of pixel-level GDP in this study from another angle.
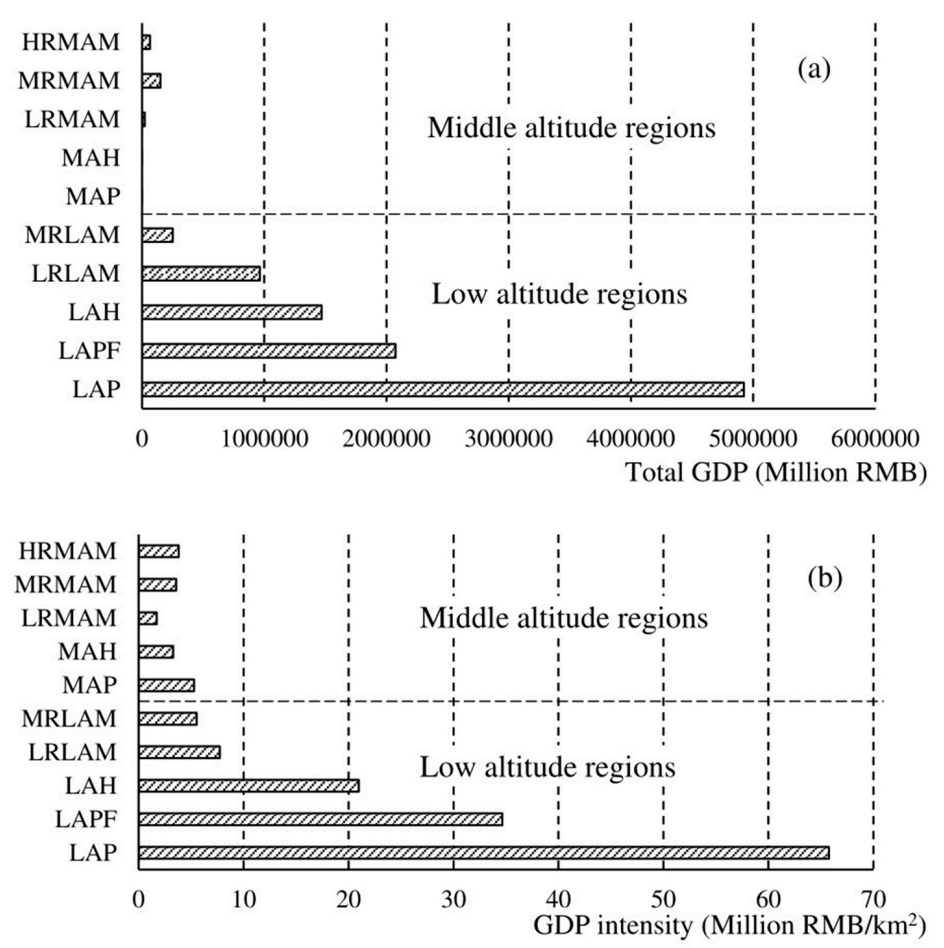

Figure 10. (a) Total GDP; and (b) GDP intensity of basic geomorphological types of South China in 2014.

\section{Discussion}

In this study, the relationships between nighttime indices and GDP at the prefecture and county level for South China in 2014 were quantitatively assessed. Since the fit between TNL and GDP at the county level proved to be more reliable, each county-level GDP was disaggregated to an individual pixel based on pixel values of corrected NPP-VIIRS data and then a linear correction method was used for GDP spatialization. Spatial variations of GDP were clearly exhibited by the GDP map. Based on this, the difference between the spatialized GDP and statistical GDP within a prefecture unit ranged from $-24,000$ Yuan to 35,000Yuan, and that within a county-level unit ranged from -34,000 Yuan to 80,000 Yuan. From the regression analysis (Figure 11), we can determine that the spatialized GDP from 
the corrected NPP-VIIRS data in 2014 basically coincided with the GDP from the statistical yearbooks, again verifying that the pixel-level GDP could accurately reflect the real status of the economy in South China in 2014.
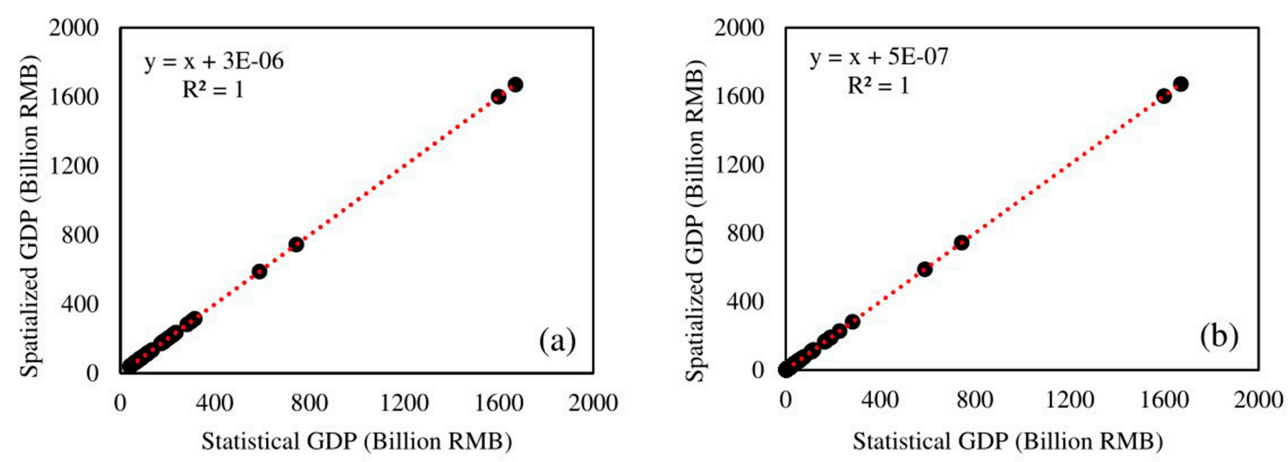

Figure 11. Relationships between statistical GDP and spatialized GDP from the corrected VIIRS data at: (a) prefecture level; and (b) county level.

Although the corrected NPP-VIIRS nighttime light data improved the accuracy of GDP estimation, results of spatialized GDP still contained some uncertainties, caused by following factors. Firstly, the reliability of statistical data directly affects the accuracy of regression models and spatialized results since the statistical data are the basis for the regression analysis. Secondly, despite the preprocessing procedures used in this study to reduce the background noise from the original NPP-VIIRS data, the corrected NPP-VIIRS data still inevitably contain some noises, which may affect the GDP estimation. Thirdly, missing statistics at county-level units may also affect the accuracy of the results. For example, during the process of statistical collection and consolidation, statistical data of a few county-level units within the same prefecture-level units were missing. To match the available statistical GDP to the boundaries of administrative units as closely as possible, county-level units with missing data, located in the same prefecture-level unit, were merged to generate a new county-level unit. Thus, the total GDP of the new unit was calculated by the total GDP of prefecture-level unit and the GDPs of county-level units, which may cause the confusion of data scale. Fourthly, using VIIRS single data, it is difficult to fully and accurately express the spatial heterogeneity of GDP distribution, and may lead to an overestimation or underestimation of GDP at the local area. For areas where steel and thermal power generation are the main industries, the local high lighting may lead to a GDP overvaluation, while for areas dominated by industries of coal and iron ore, lighting cannot fully reflect GDP output, resulting in a lower estimation of GDP. In summary, it is likely to enhance the accuracy of GDP estimation by improving the availability and quality of statistical data and NPP-VIIRS data, introducing multi-source data and optimizing the methods of nighttime light data correction. In addition, responses of NPP-VIIRS nighttime light data to economic activities vary across study areas, scales and periods. Understanding how to quantify the diverse relationships between light brightness and economic parameters and build a common model for all cases may be the key issue for the evaluation of regional GDP in a quick and reliable way.

The major contributions of this study are twofold. Firstly, previous studies have used linear or log-linear models to statistically fit the relationships between the locally average or total nighttime light radiance and corresponding socioeconomic variables across the county-level, prefecture-level and province-level scales, whereas this research calculated common nighttime light indices of statistical units at different scales and explored the best fitting model for each case. Accordingly, the notable advantage of TNL in predicting GDP was verified and the quadratic polynomial model was proved to be more suitable in fitting the relationships between locally TNL and GDP rather than the simple linear relationship used in previous studies. Secondly, although the utility of NPP-VIIRS nighttime light data for assessing economic activities has been extensively verified through the significant correlations 
of nighttime light brightness and corresponding economic variables, no research has reported the ability of NPP-VIIRS data to estimate pixel-level GDP. The spatialized GDP in this study was obtained through linear correction, which greatly reduced the deviation of pixel-level GDP simulated by the pixel value of light brightness. The spatialization of GDP provides more accurate and efficient data sources for GDP statistics at pixel-level scales, which will benefit a comprehensive understanding of the dynamics of local economies and the decision making for sustainable economic development.

When analyzing the economic spatial distribution of South China, we mainly focused on the economic differences among diverse geomorphological types. Compared to the influence of anthropogenic factors, that of topography and geomorphology on economic development has gradually declined. However, no previous study has clearly demonstrated that the role of landform can be ignored. Although it seems that we did not find any new findings from the quantitative results in 2014, with the accelerated urbanization and industrial transformation, analysis on long-term spatial-temporal differences of economic status among different geomorphological types would help to obtain valuable findings, which is of great significance for regional sustainable development.

Since statistical data in 2015 were not available at the beginning of this experiment, the statistical data and monthly NPP-VIIRS nighttime light images in 2014 were selected to study the latest economic pattern of South China. Currently, a series of NPP-VIIRS data are available including monthly composites from April 2012 to November 2016. As NOAA/NGDC is working to produce more NPP-VIIRS data with higher quality, further research can be focused on multi-temporal image analysis for revealing the spatiotemporal patterns of GDP. In addition, other types of data, including geomorphological data, land cover data, population data, disaster data, and ecological data shall be applied to study economic development and its impact on the ecological environment and human activities, and to explore the coupled mechanism between economic development and ecological environment.

\section{Conclusions}

GDP is an important indicator for reflecting the intensity of economic activities, and the spatialization of GDP can provide an important basis for the overlay analysis of natural and human factors. In this study, composite annual NPP-VIIRS data were obtained by averaging the pixel brightness of monthly NPP-VIIRS nighttime light data. As the composite NPP-VIIRS data are a preliminary product, a sequence of correction procedures were employed to reduce the background noises and high-value anomalies. Based on the corrected NPP-VIIRS data, optimal regression models between the nighttime light indices and corresponding GDP statistical data at both the prefecture and county level were established. Through the analysis of estimated results, the best regression model was selected to spatialize the GDP, and the spatial distribution of GDP was produced based on a pixel size of $500 \mathrm{~m} \times 500 \mathrm{~m}$ in South China in 2014. Finally, using the basic geomorphological types in South China, we analyzed the spatial characteristics of GDP within different geomorphological units in South China to explore the intensity of economic activities under different geomorphological environments.

The TNL brightness was found to exhibit a strong capacity in reflecting the real status of the regional economy. Quadratic polynomial relationships were found between the TNL brightness of NPP-VIIRS data and the corresponding GDP at both prefecture level and county level in the case study for South China, among which the corrected NPP-VIIRS nighttime light data showed a better fit than the original data, and the county-level fit was better than the prefecture-level fit.

The linearized correction of the simulated GDP greatly improved the accuracy of GDP estimation, resulting in a more realistic and detailed reflection of the spatial distribution of GDP in South China in 2014. The GDP of coastal areas was generally higher than that of inland areas, and the economy of the Pearl River Delta region was extremely active.

The total GDP and its intensity in the low altitude region of South China were significantly higher than those in the middle altitude region. Compared with platforms, hills and mountains, the economy in plains was more active, especially plains in the low altitude region. The low altitude plain 
was the most economically developed area in South China, followed by low altitude platforms and low altitude hills. Economic development in the middle altitude region and low altitude hills and mountains remained to be strengthened. These results are consistent with our general understandings, and will contribute to verifying the accuracy of pixel-level GDP from another angle.

Acknowledgments: The authors express gratitude to Yongbo Liu at University of Guelph, Canada and anonymous reviewers for improving the manuscript. This study was supported by the Surveying and Mapping Geoinformation Nonprofit Specific Project (201512033), the Major State Basic Research Development Program of China (2015CB954101), and the National Natural Science Foundation of China (41171332 and 41571388 ).

Author Contributions: Min Zhao and Weiming Cheng conceived and designed the experiments; Min Zhao and Chenghu Zhou performed the experiments; Zhao Min, Weiming Cheng, Chenghu Zhou, and Manchun Li analyzed the data; and Min Zhao, Weiming Cheng, Nan Wang and Qiangyi Liu wrote the paper.

Conflicts of Interest: The authors declare no conflict of interest.

\section{Appendix A}

Table A1. A list of the prefecture-level and county-level administrative units for South China. The county-level units we used are in the last column.

\begin{tabular}{|c|c|c|c|}
\hline Province & Prefecture-Level Unit & Original County-Level Unit & Final County-Level Unit \\
\hline Guangdong & Guangzhou & Guangzhou Municipality & \multirow{3}{*}{$\begin{array}{l}\text { Guangzhou and Zengcheng and } \\
\text { Conghua }\end{array}$} \\
\hline Guangdong & Guangzhou & Zengcheng Municipality & \\
\hline Guangdong & Guangzhou & Conghua Municipality & \\
\hline Guangdong & Shaoguan & Shaoguan Municipality & \multirow{2}{*}{ Shaoguan and Qujiang } \\
\hline Guangdong & Shaoguan & Qujiang County & \\
\hline Guangdong & Shaoguan & Shixing County & Shixing County \\
\hline Guangdong & Shaoguan & Renhua County & Renhua County \\
\hline Guangdong & Shaoguan & Wengyuan County & Wengyuan County \\
\hline Guangdong & Shaoguan & Ruyuan Yao A.C. & Ruyuan Yao A.C. \\
\hline Guangdong & Shaoguan & Xinfeng County & Xinfeng County \\
\hline Guangdong & Shaoguan & Lechang Municipality & Lechang Municipality \\
\hline Guangdong & Shaoguan & Nanxiong Municipality & Nanxiong Municipality \\
\hline Guangdong & Shenzhen & Shenzhen Municipality & Shenzhen Municipality \\
\hline Guangdong & Zhuhai & Zhuhai Municipality & Zhuihai Municipality \\
\hline Guangdong & Shantou & Shantou Municipality & Shantou Municipality \\
\hline Guangdong & Shantou & Nan'ao County & Nan'ao County \\
\hline Guangdong & Foshan & Foshan Municipality & Foshan Municipality \\
\hline Guangdong & Jiangmen & Jiangmen Municipality & Jiangmen Municipality \\
\hline Guangdong & Jiangmen & Taishan Municipality & Taishan Municipality \\
\hline Guangdong & Jiangmen & Kaiping Municipality & Kaiping Municipality \\
\hline Guangdong & Jiangmen & Heshan Municipality & Heshan Municipality \\
\hline Guangdong & Jiangmen & Enping Municipality & Enping Municipality \\
\hline Guangdong & Zhanjiang & Zhanjiang Municipality & Zhanjiang Municipality \\
\hline Guangdong & Zhanjiang & Suixi County & Suixi County \\
\hline Guangdong & Zhanjiang & Xuwen County & Xuwen County \\
\hline Guangdong & Zhanjiang & Lianjiang Municipality & Lianjiang Municipality \\
\hline Guangdong & Zhanjiang & Leizhou Municipality & Leizhou Municipality \\
\hline Guangdong & Zhanjiang & Wuchuan Municipality & Wuchuan Municipality \\
\hline Guangdong & Maoming & Maoming Municipality & \multirow{2}{*}{ Maoming and Dianbai } \\
\hline Guangdong & Maoming & Dianbai County & \\
\hline Guangdong & Maoming & Gaozhou Municipality & Gaozhou Municipality \\
\hline Guangdong & Maoming & Huazhou Municipality & Huazhou Municipality \\
\hline Guangdong & Maoming & Xinyi Municipality & Xinyi Municipality \\
\hline Guangdong & Zhaoqing & Zhaoqing Municipality & Zhaoqing Municipality \\
\hline Guangdong & Zhaoqing & Guangning County & Guangning County \\
\hline Guangdong & Zhaoqing & Huaiji County & Huaiji County \\
\hline Guangdong & Zhaoqing & Fengkai County & Fengkai County \\
\hline Guangdong & Zhaoqing & Deqing County & Deqing County \\
\hline Guangdong & Zhaoqing & Gaoyao Municipality & Gaoyao Municipality \\
\hline Guangdong & Zhaoqing & Sihui Municipality & Sihui Municipality \\
\hline Guangdong & Huizhou & Huizhou Municipality & Huizhou Municipality \\
\hline
\end{tabular}


Table A1. Cont.

\begin{tabular}{|c|c|c|c|}
\hline Province & Prefecture-Level Unit & Original County-Level Unit & Final County-Level Unit \\
\hline Guangdong & Huizhou & Boluo County & Boluo County \\
\hline Guangdong & Huizhou & Huidong County & Huidong County \\
\hline Guangdong & Huizhou & Longmen County & Longmen County \\
\hline Guangdong & Meizhou & Meizhou Municipality & \\
\hline Guangdong & Meizhou & Mei County & Meizhou and Mei \\
\hline Guangdong & Meizhou & Dapu County & Dapu County \\
\hline Guangdong & Meizhou & Fengshun County & Fengshun County \\
\hline Guangdong & Meizhou & Wuhua County & Wuhua County \\
\hline Guangdong & Meizhou & Pingyuan County & Pingyuan County \\
\hline Guangdong & Meizhou & Jiaoling County & Jiaoling County \\
\hline Guangdong & Meizhou & Xingning Municipality & Xingning Municipality \\
\hline Guangdong & Shanwei & Shanwei Municipality & Shanwei Municipality \\
\hline Guangdong & Shanwei & Haifeng County & Haifeng County \\
\hline Guangdong & Shanwei & Luhe County & Luhe County \\
\hline Guangdong & Shanwei & Lufeng Municipality & Lufeng Municipality \\
\hline Guangdong & Heyuan & Heyuan Municipality & Heyuan Municipality \\
\hline Guangdong & Heyuan & Zijin County & Zijin County \\
\hline Guangdong & Heyuan & Longchuan County & Longchuan County \\
\hline Guangdong & Heyuan & Lianping County & Lianping County \\
\hline Guangdong & Heyuan & Heping County & Heping County \\
\hline Guangdong & Heyuan & DongYuan County & DongYuan County \\
\hline Guangdong & Yangjiang & Yangjiang Municipality & \\
\hline Guangdong & Yangjiang & Yangdong County & Yangjiang and Yangdong \\
\hline Guangdong & Yangjiang & Yangxi County & Yangxi County \\
\hline Guangdong & Yangjiang & Yangchun Municipality & Yangchun Municipality \\
\hline Guangdong & Qingyuan & Qingyuan Municipality & \\
\hline Guangdong & Qingyuan & Qingxin County & Qiangyuan and Qingxin \\
\hline Guangdong & Qingyuan & Fogang County & Fogang County \\
\hline Guangdong & Qingyuan & Yangshan County & Yangshan County \\
\hline Guangdong & Qingyuan & $\begin{array}{l}\text { Lianshan Zhuang and Yao } \\
\text { A.C. }\end{array}$ & Lianshan Zhuang and Yao A.C. \\
\hline Guangdong & Qingyuan & Liannan Yao A.C. & Liannan Yao A.C. \\
\hline Guangdong & Qingyuan & Yingde Municipality & Yingde Municipality \\
\hline Guangdong & Qingyuan & Lianzhou Municipality & Lianzhou Municipality \\
\hline Guangdong & Dongguan & Dongguan Municipality & Dongguan Municipality \\
\hline Guangdong & Zhongshan & Zhongshan Municipality & Zhongshan Municipality \\
\hline Guangdong & Chaozhou & Chaozhou Municipality & \\
\hline Guangdong & Chaozhou & Chaoan County & Chaozhou and Chaoan \\
\hline Guangdong & Chaozhou & Raoping County & Raoping County \\
\hline Guangdong & Jieyang & Jieyang Municipality & \\
\hline Guangdong & Jieyang & Jiedong County & Jieyang and Jiedong \\
\hline Guangdong & Jieyang & Jiexi County & Jiexi County \\
\hline Guangdong & Jieyang & Huilai County & Huilai County \\
\hline Guangdong & Jieyang & Puning Municipality & Puning Municipality \\
\hline Guangdong & Yunfu & Yunfu Municipality & \\
\hline Guangdong & Yunfu & Yun'an County & Yunfu and Yun'an \\
\hline Guangdong & Yunfu & Xinxing County & Xinxing County \\
\hline Guangdong & Yunfu & Yu'nan County & Yu'nan County \\
\hline Guangdong & Yunfu & Luoding Municipality & Luoding Municipality \\
\hline Guangxi & Nanning & Nanning Municipality & Nanning Municipality \\
\hline Guangxi & Nanning & Yongning County & Yongning County \\
\hline Guangxi & Nanning & Wuming County & Wuming County \\
\hline Guangxi & Nanning & Longan County & Longan County \\
\hline Guangxi & Nanning & Mashan County & Mashan County \\
\hline Guangxi & Nanning & Shanglin County & Shanglin County \\
\hline Guangxi & Nanning & Binyang County & Binyang County \\
\hline Guangxi & Nanning & Heng County & Heng County \\
\hline Guangxi & Liuzhou & Liuzhou Municipality & Liuzhou Municipality \\
\hline Guangxi & Liuzhou & Liujiang County & Liujiang County \\
\hline Guangxi & Liuzhou & Liucheng County & Liucheng County \\
\hline Guangxi & Liuzhou & Luzhai County & Luzai County \\
\hline
\end{tabular}


Table A1. Cont.

\begin{tabular}{|c|c|c|c|}
\hline Province & Prefecture-Level Unit & Original County-Level Unit & Final County-Level Unit \\
\hline Guangxi & Liuzhou & Rongan County & Rongan County \\
\hline Guangxi & Liuzhou & Rongshui Miao A.C. & Rongshui Miao A.C. \\
\hline Guangxi & Liuzhou & Sanjiang Dong A.C. & Sanjiang Dong A.C. \\
\hline Guangxi & Guilin & Guilin Municipality & Guilin Municipality \\
\hline Guangxi & Guilin & Yangshuo County & Yangshuo County \\
\hline Guangxi & Guilin & Lingui County & Lingui County \\
\hline Guangxi & Guilin & Lingchuan County & Lingchuan County \\
\hline Guangxi & Guilin & Quanzhou County & Quanzhou County \\
\hline Guangxi & Guilin & Xing'an County & Xing'an County \\
\hline Guangxi & Guilin & Yongfu County & Yongfu County \\
\hline Guangxi & Guilin & Guanyang County & Guanyang County \\
\hline Guangxi & Guilin & Longsheng Ge A.C. & Longsheng Ge A.C. \\
\hline Guangxi & Guilin & Ziyuan County & Ziyuan County \\
\hline Guangxi & Guilin & Pingle County & Pingle County \\
\hline Guangxi & Guilin & Lipu County & Lipu County \\
\hline Guangxi & Guilin & Gongcheng Yao A.C. & Gongcheng Yao A.C. \\
\hline Guangxi & Wuzhou & Wuzhou Municipality & Wuzhou Municipality \\
\hline Guangxi & Wuzhou & Cangwu County & Cangwu County \\
\hline Guangxi & Wuzhou & Teng County & Teng County \\
\hline Guangxi & Wuzhou & Mengshan County & Mengshan County \\
\hline Guangxi & Wuzhou & Cenxi Municipality & Cenxi Municipality \\
\hline Guangxi & Beihai & Beihai Municipality & Beihai Municipality \\
\hline Guangxi & Beihai & Hepu County & Hepu County \\
\hline Guangxi & Fangchenggang & Fangchenggang Municipality & Fangchenggang Municipality \\
\hline Guangxi & Fangchenggang & Fangcheng District & Fangcheng District \\
\hline Guangxi & Fangchenggang & Shangsi County & Shangsi County \\
\hline Guangxi & Fangchenggang & Dongxing Municipality & Dongxing Municipality \\
\hline Guangxi & Qinzhou & Qinzhou Municipality & Qinzhou Municipality \\
\hline Guangxi & Qinzhou & Qinbei District & Qinbei District \\
\hline Guangxi & Qinzhou & Lingshan County & Lingshan County \\
\hline Guangxi & Qinzhou & Pubei County & Pubei County \\
\hline Guangxi & Guigang & Guigang Municipality & Guigang Municipality \\
\hline Guangxi & Guigang & Gangbei District & \\
\hline Guangxi & Guigang & Qintang District & Gangbei and Qintang \\
\hline Guangxi & Guigang & Pingnan County & Pingnan County \\
\hline Guangxi & Guigang & Guiping Municipality & Guiping Municipality \\
\hline Guangxi & Yulin & Yulin Municipality & Yulin Municipality \\
\hline Guangxi & Yulin & Rong County & Rong County \\
\hline Guangxi & Yulin & Luchuan County & Luchuan County \\
\hline Guangxi & Yulin & Bobai County & Bobai County \\
\hline Guangxi & Yulin & Xingye County & Xingye County \\
\hline Guangxi & Yulin & Beiliu Municipality & Beiliu Municipality \\
\hline Guangxi & Baise & Baise Municipality & Baise Municipality \\
\hline Guangxi & Baise & Tianyang County & Tianyang County \\
\hline Guangxi & Baise & Tiandong County & Tiandong County \\
\hline Guangxi & Baise & Pingguo County & Pingguo County \\
\hline Guangxi & Baise & Debao County & Debao County \\
\hline Guangxi & Baise & Jingxi County & Jingxi County \\
\hline Guangxi & Baise & Napo County & Napo County \\
\hline Guangxi & Baise & Lingyun County & Lingyun County \\
\hline Guangxi & Baise & Leye County & Leye County \\
\hline Guangxi & Baise & Tianlin County & Tianlin County \\
\hline Guangxi & Baise & Xilin County & Xilin County \\
\hline Guangxi & Baise & Longlin Ge A.C. & Longlin Ge A.C. \\
\hline Guangxi & Hezhou & Hezhou Municipality & Hezhou Municipality \\
\hline Guangxi & Hezhou & Zhaoping County & Zhaoping County \\
\hline Guangxi & Hezhou & Zhongshan County & Zhongshan County \\
\hline Guangxi & Hezhou & Fuchuan Yao A.C. & Fuchuan Yao A.C. \\
\hline Guangxi & Hechi & Hechi Municipality & Hechi Municipality \\
\hline
\end{tabular}


Table A1. Cont.

\begin{tabular}{|c|c|c|c|}
\hline Province & Prefecture-Level Unit & Original County-Level Unit & Final County-Level Unit \\
\hline Guangxi & Hechi & Nandan County & Nandan County \\
\hline Guangxi & Hechi & Tiane County & Tiane County \\
\hline Guangxi & Hechi & Fengshan County & Fengshan County \\
\hline Guangxi & Hechi & Donglan County & Donglan County \\
\hline Guangxi & Hechi & Luocheng Mulao A.C. & Luocheng Mulao A.C. \\
\hline Guangxi & Hechi & Huanjiang Maonan A.C. & Huangjiang Maonan A.C. \\
\hline Guangxi & Hechi & Bama Yao A.C. & Bama Yao A.C. \\
\hline Guangxi & Hechi & Du'an Yao A.C. & Du'an Yao A.C. \\
\hline Guangxi & Hechi & Dahua Yao A.C. & Dahua Yao A.C. \\
\hline Guangxi & Hechi & Yizhou Municipality & Yizhou Municipality \\
\hline Guangxi & Laibin & Laibin Municipality & Laibin Municipality \\
\hline Guangxi & Laibin & Xincheng County & Xincheng County \\
\hline Guangxi & Laibin & Xiangzhou County & Xiangzhou County \\
\hline Guangxi & Laibin & Wuxuan County & Wuxuan County \\
\hline Guangxi & Laibin & Jinxiu Yao A.C. & Jinxiu Yao A.C. \\
\hline Guangxi & Laibin & Heshan Municipality & Heshan Municipality \\
\hline Guangxi & Chongzuo & Chongzuo Municipality & Chongzuo Municipality \\
\hline Guangxi & Chongzuo & Fusui County & Fusui County \\
\hline Guangxi & Chongzuo & Ningming County & Ningming County \\
\hline Guangxi & Chongzuo & Longzhou County & Longzhou County \\
\hline Guangxi & Chongzuo & Daxin County & Daxin County \\
\hline Guangxi & Chongzuo & Tiandeng County & Tiandeng County \\
\hline Guangxi & Chongzuo & Pingxiang Municipality & Pingxiang Municipality \\
\hline Hainan & Haikou & Haikou Municipality & Haikou Municipality \\
\hline Hainan & Sanya & Sanya Municipality & Sanya Municipality \\
\hline Hainan & Provincial county & Wuzhishan Municipality & Wuzhishan Municipality \\
\hline Hainan & Provincial county & Qionghai Municipality & Qionghai Municipality \\
\hline Hainan & Provincial county & Danzhou Municipality & Danzhou Municipality \\
\hline Hainan & Provincial county & Wenchang Municipality & Wenchang Municipality \\
\hline Hainan & Provincial county & Wanning Municipality & Wanning Municipality \\
\hline Hainan & Provincial county & Dongfang Municipality & Dongfang Municipality \\
\hline Hainan & Provincial county & Ding'an County & Ding'an County \\
\hline Hainan & Provincial county & Tunchang County & Tunchang County \\
\hline Hainan & Provincial county & Chengmai County & Chengmai County \\
\hline Hainan & Provincial county & Lingao County & Lingao County \\
\hline Hainan & Provincial county & Baisha Li A.C. & Baisha Li A.C. \\
\hline Hainan & Provincial county & Changjiang Li A.C. & Changjiang Li A.C. \\
\hline Hainan & Provincial county & Ledong Li A.C. & Ledong Li A.C. \\
\hline Hainan & Provincial county & Lingshui Li A.C. & Lingshui Li A.C. \\
\hline Hainan & Provincial county & Baoting Li and Miao A.C. & Baoting Li and Miao A.C. \\
\hline Hainan & Provincial county & Qiongzhong Li and Miao A.C. & Qiongzhong Li and Miao A.C. \\
\hline
\end{tabular}

${ }^{1}$ A.C. is the abbreviation of Autonomous County.

\section{References}

1. Elvidge, C.D.; Baugh, K.E.; Kihn, E.A.; Kroehl, H.W.; Davis, E.R.; Davis, C.W. Relation between satellite observed visible-near infrared emissions, population, economic activity and electric power consumption. Int. J. Remote. Sens. 1997, 18, 1373-1379. [CrossRef]

2. Doll, C.N.H.; Muller, J.P.; Morley, J.G. Mapping regional economic activity from night-time light satellite imagery. Ecol. Econ. 2006, 57, 75-92. [CrossRef]

3. Zhao, N.Z.; Currit, N.; Samson, E. Net primary production and gross domestic product in China derived from satellite imagery. Ecol. Econ. 2011, 70, 921-928. [CrossRef]

4. Forbes, D.J. Multi-scale analysis of the relationship between economic statistics and DMSP-OLS night light images. GISci. Remote. Sens. 2013, 50, 483-499. [CrossRef]

5. Doll, C.N.H.; Muller, J.P.; Elvidge, C.D. Night-time imagery as a tool for global mapping of socioeconomic parameters and greenhouse gas emissions. Ambio 2000, 29, 157-162. [CrossRef]

6. Ghosh, T.; Powell, R.L.; Elvidge, C.D.; Baugh, K.E.; Sutton, P.C.; Anderson, S. Shedding light on the global distribution of economic activity. Open Geogr. J. 2010, 3, 148-161. [CrossRef] 
7. Letu, H.; Hara, M.; Yagi, H.; Naoki, K.; Tana, G.; Nishio, F.; Shuhei, O. Estimating energy consumption from night-time DMPS/OLS imagery after correcting for saturation effects. Int. J. Remote. Sens. 2010, 31, 4443-4458. [CrossRef]

8. Zhao, N.Z.; Ghosh, T.; Samson, E. Mapping spatio-temporal changes of Chinese electric power consumption using night-time imagery. Int. J. Remote. Sens. 2012, 33, 6304-6320. [CrossRef]

9. Baugh, K.; Hsu, F.C.; Elvidge, C.; Zhizhin, M. Nighttime lights compositing using the VIIRS day-night band: Preliminary results. Proc. Asia Pac. Adv. Netw. 2013, 35, 70-86. [CrossRef]

10. Elvidge, C.D.; Baugh, K.; Zhizhin, M.; Hsu, F.C. Why VIIRS data are superior to DMSP for mapping nighttime lights. Proc. Asia Pac. Adv. Netw. 2013, 35, 62-69. [CrossRef]

11. Li, X.; Xu, H.M.; Chen, X.L.; Li, C. Potential of NPP-VIIRS nighttime light imagery for modeling the regional economy of China. Remote. Sens. 2013, 5, 3057-3081. [CrossRef]

12. Ma, T.; Zhou, C.H.; Pei, T.; Haynie, S.; Fan, J.F. Responses of Suomi-NPP VIIRS-derived nighttime lights to socioeconomic activity in China's cities. Remote. Sens. Lett. 2014, 5, 165-174. [CrossRef]

13. Shi, K.F.; Yu, B.L.; Huang, Y.X.; Hu, Y.J.; Yin, B.; Chen, Z.Q.; Chen, L.J.; Wu, J.P. Evaluating the ability of NPP-VIIRS nighttime light data to estimate the gross domestic product and the electric power consumption of China at multiple scales: A comparison with DMSP-OLS data. Remote. Sens. 2014, 6, 1705-1724. [CrossRef]

14. Elvidge, C.D.; Ziskin, D.; Baugh, K.E.; Tuttle, B.T.; Ghosh, T.; Pack, D.W.; Erwin, E.H.; Zhizhin, M. A fifteen year record of global natural gas flaring derived from satellite data. Energies 2009, 2, 595-622. [CrossRef]

15. Ma, T.; Zhou, Y.K.; Zhou, C.H.; Haynie, S.; Pei, T.; Xu, T. Night-time light derived estimation of spatio-temporal characteristics of urbanization dynamics using DMSP/OLS satellite data. Remote. Sens. Environ. 2015, 158, 453-464. [CrossRef]

16. Propastin, P.; Kappas, M. Assessing satellite-observed nighttime lights for monitoring socioeconomic parameters in the Republic of Kazakhstan. GISci. Remote. Sens. 2012, 49, 538-557. [CrossRef]

17. Cheng, W.M.; Zhou, C.H.; Chai, H.X.; Zhao, S.M.; Liu, H.J.; Zhou, Z.P. Research and compilation of the Geomorphologic Atlas of the People's Republic of China (1:1,000,000). J. Geogr. Sci. 2011, 21, 89-100. [CrossRef]

18. Cheng, W.M.; Zhou, C.H.; Li, B.Y.; Shen, Y.C.; Zhang, B.P. Structure and contents of layered classification system of digital geomorphology for China. J. Geogr. Sci. 2011, 21, 771-790. [CrossRef]

19. He, W.C.; Zhao, S.M.; Cheng, W.M. Analysis of land cover change on basic geomorphic types in Shanxi Province. J. Geo-Inf. Sci. 2016, 18, 210-219. (In Chinese) [CrossRef]

20. Zhao, M.; Cheng, W.M.; Huang, K.; Wang, N.; Liu, Q.Y. Research on land cover change in Beijing-Tianjin-Hebei Region during the last 10 years based on different geomorphic units. J. Nat. Res. 2016, 31, 252-264. (In Chinese) [CrossRef]

21. Zhao, M.; Cheng, W.M.; Huang, K. Spatial characteristics of urban development and its correlation with macro geomorphology in Beijing-Tianjin-Hebei Region for recent 21 years. J. Geo-Inf. Sci. 2015, 17, 917-926. (In Chinese) [CrossRef]

22. Zhao, M.; Cheng, W.M.; Liu, Q.Y.; Wang, N. Spatiotemporal measurement of urbanization levels based on multiscale units: A case study of the Bohai Rim Region in China. J. Geogr. Sci. 2016, 26, 531-548. [CrossRef]

23. Zhao, M.; Cheng, W.M.; Zhou, C.H.; Li, M.C.; Wang, N.; Liu, Q.Y. Spatial differentiation and morphologic characteristics of China's urban core zones based on geomorphologic partition. J. Appl. Remote. Sens. 2017, 11, 016041. [CrossRef]

24. Cheng, W.M.; Chai, H.X.; Fang, Y.; Zhou, C.H.; Tian, C.Y. Analysis of cultivated land based on water resources regionalization and geomorphologic characteristics in Xinjiang, China. J. Nat. Res. 2012, 27, 1809-1822. (In Chinese) [CrossRef]

25. Fang, Y.; Cheng, W.M.; Zhou, C.H.; Chen, X.; Tian, C.Y. Suitability evaluation of land cultivation in Xinjiang based on multiple natural geographical factors. J. Geo-Inf. Sci. 2015, 17, 846-854. (In Chinese) [CrossRef]

26. Schroeder, W.; Oliva, P.; Giglio, L.; Csiszar, I.A. The new VIIRS $375 \mathrm{~m}$ active fire detection data product: Algorithm description and initial assessment. Remote. Sens. Environ. 2014, 143, 85-96. [CrossRef]

27. Shi, K.F.; Yu, B.L.; Hu, Y.J.; Huang, C.; Chen, Y.; Huang, Y.X.; Chen, Z.Q.; Wu, J.P. Modeling and mapping total freight traffic in China using NPP-VIIRS nighttime light composite data. GISci. Remote. Sens. 2015, 52, 274-289. [CrossRef]

28. Ma, T.; Zhou, Y.K.; Wang, Y.J.; Zhou, C.H.; Haynie, S.; Xu, T. Diverse relationships between Suomi-NPP VIIRS night-time light and multi-scale socioeconomic activity. Remote. Sens. Lett. 2014, 5, 652-661. [CrossRef] 
29. Chen, J.; Zhuo, L.; Shi, P.J.; Ichinose, T. The study on urbanization process in China based on DMSP/OLS data: Development of a light index for urbanization level estimation. J. Remote. Sens. 2003, 7, 168-175. (In Chinese) [CrossRef]

30. Zhuo, L.; Shi, P.J.; Chen, J.; Ichinose, T. Application of compound night light index derived from DMSP/OLS data to urbanization analysis in China in the 1990s. Acta Geogr. Sin. 2003, 58, 893-902. (In Chinese) [CrossRef]

31. Chen, X.; Nordhaus, W. A test of the new VIIRS lights data set: Population and economic output in Africa. Remote. Sens. 2015, 7, 4937-4947. [CrossRef]

32. Yu, B.L.; Shi, K.F.; Hu, Y.J.; Huang, C.; Chen, Z.Q.; Wu, J.P. Poverty Evaluation Using NPP-VIIRS Nighttime Light Composite Data at the County Level in China. IEEE J. Sel. Top. Appl. Earth Obs. Remote. Sens. 2015, 8, 1217-1229. [CrossRef]

33. Li, F.; Wei, A.X.; Mi, X.N.; Sun, G.T. An approach of GDP spatialization in Hebei province using NPP-VIIRS nighttime light data. J. Xinyang Norm. Univ.: Nat. Sci. Ed. 2016, 29, 152-156. (In Chinese) [CrossRef]

2017 by the authors. Licensee MDPI, Basel, Switzerland. This article is an open access article distributed under the terms and conditions of the Creative Commons Attribution (CC BY) license (http://creativecommons.org/licenses/by/4.0/). 